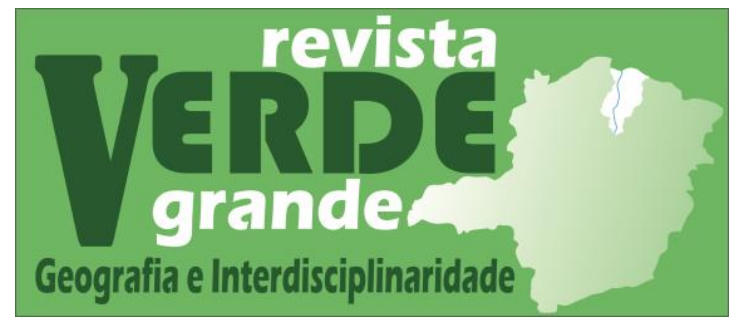

Volume 2, no. 2 (2020)

ISSN: 2675-2395

https://doi.org/10.46551/rvg2675239520202135142

\title{
DINÂMICA DOS SOLOS BRASILEIROS E TÉCNICA ALTERNATIVA PARA MEDIÇÃO DO PH DO SOLO, UTILIZANDO EXTRATO DE REPOLHO ROXO
}

\author{
Dynamic of Brazilian Soils and Alternative Technique for Measuring Soil, Using Purple Cabbage Extract
}

Vanessa Pagno ${ }^{1}$ https://orcid.org/0000-0002-9885-3356

Fabiana Pagno ${ }^{2}$ https://orcid.org/0000-0003-0993-5876

Alan Rafael Coineth de Souza ${ }^{3}$ https://orcid.org/0000-0002-1004-8345

Daniella Rosa Marques de Oliveira ${ }^{4}$ https://orcid.org/0000-0003-1552-1178

\footnotetext{
${ }^{1}$ Pós-Graduação em Química - UNIOESTE. E-mail: wanessapgno@ hotmail.com

${ }^{2}$ Pós-Graduação em Geografia - UNIOESTE. E-mail: fabianapagno2@ gmail.com

${ }^{3}$ Pós-Graduação em Geografia - UNIOESTE. E-mail: alancoineth@ hotmail.com

${ }^{4}$ Pós-Graduação em Geografia - UNIOESTE. E-mail: daniella.rosa.m@ hotmail.com
}

\section{Resumo}

No presente relato de experiência, é destacada uma atividade prática que teve como objetivo a realização de experiências com uma técnica alternativa de obtenção de $\mathrm{pH}$ do solo, utilizando extrato de repolho roxo como indicador, para auxiliar na compreensão deste conceito e compará-lo com a realidade de solos brasileiros. Esta atividade foi realizada em um minicurso desenvolvido durante o XXII Encontro de Geografia (ENGEO) e XVI Encontro de Geografia do Sudoeste do Paraná (ENGESOP), promovido pelos colegiados dos cursos de Geografia da Universidade Estadual do Oeste do Paraná (UNIOESTE) - Campus Francisco Beltrão - PR, no ano de 2019. Neste trabalho, relata-se as experiências vivenciadas durante a atividade, os objetivos alcançados, discussões sobre os temas propostos e realização de atividades experimentais de medição do $\mathrm{pH}$ de substâncias diversas e de três tipos de solo, bem como a discussão dos valores de $\mathrm{pH}$ e sua relação com os diferentes solos brasileiros.

Palavras-chave: Tipos de solos brasileiros. Intemperismo. Medição do pH do solo.

\begin{abstract}
In the present experience report, a practical activity that aimed to carry out experiments with an alternative technique for obtaining soil $\mathrm{pH}$ using red cabbage extract as an indicatories described, in order to understand this concept and compare it with the reality of Brazilian soils. This activity was carried out in a workshop given during the XXII Geography Meeting (ENGEO) and XVI Meeting of Geography of the Southwest of Paraná (ENGESOP), promoted by the collegiate of the Geography courses of the State University of the West of Paraná (UNIOESTE) - Francisco Beltrão, Campus PR, in the year 2019. With the discussions and activities carried out, the participants of the workshop were able to obtain a new vision of the concept of $\mathrm{pH}$, regarding everyday products and the types of
\end{abstract}


Vanessa Pagno; Fabiana Pagno; Alan Rafael Coineth de Souza; Daniella Rosa Marques de Oliveira.

Brazilian soils, as well as the anthropic and weathering factors that influence the $\mathrm{pH}$ of different soil types.

Keywords: Brazilian soil types. Weathering pH soil.

\section{Introdução}

$\mathrm{Na}$ Geografia física é de extrema importância compreender alguns conceitos como tipos de solo, processos de intemperismo que atuam nos solos, sobre o que é pH e as conseqüências de sua alteração no solo, geralmente ocasionados por ação de intemperismo ou ação antrópica. O conceito de solo é dado pela EMBRAPA (2018), que considera o solo como corpos naturais, formados por partes sólidas, líquidas e gasosas, contendo materiais minerais e orgânicos e que se encontram no manto superficial do planeta, podendo conter matéria viva, ser vegetados e ter sofrido modificações antrópicas. Os principais tipos de solo conhecidos são argissolos, cambissolos, chernossolos, espodossolos, gleissolos, latossolos, luvissolos, neossolos, nitossolos, organossolos, planossolos, plintossolos e vertissolos (EMBRAPA, 2018).

O intemperismo que ocorre no solo, por sua vez, segundo Sardinha e colaboradores (2019), pode ser considerado como fenômenos resultantes de ações dos elementos da natureza, como a água $\left(\mathrm{H}_{2} \mathrm{O}\right)$, gás carbônico $\left(\mathrm{CO}_{2}\right)$ e temperatura. Esses compostos juntos podem acabar alterando os minerais primários das rochas e torná-los minerais secundários em solos residuais e soluções lixiviadas (SARDINHA, GODOY, CONCEIÇÃO, 2019), alterando a mineralogia e as propriedades físicas das rochas (LEÃO et al., 2017). Desta maneira, o intemperismo pode ser compreendido como uma perda geoquímica, em que os elementos químicos são retidos do solo (íons), principalmente pela ação das águas e drenados pelas bacias hidrográficas (SARDINHA, GODOY, CONCEIÇÃO, 2019).

As ações antrópicas do solo e ações de intemperismo podem influenciar na alteração do $\mathrm{pH}$ dos solos. Por isso, faz-se necessário compreender o conceito de $\mathrm{pH}$ do solo, para, posteriormente, entender como sua alteração é significativa. O potencial hidrogeniônico $(\mathrm{pH})$ do solo pode ser determinado como a quantidade de íons $\mathrm{H}^{+}$presente em solução (YOSHIOKA, LIMA, 2005; ANTUNES et al., 2009). Em solos com íons trocáveis, que retêm íon $\mathrm{H}^{+}$, o solo tende a ficar mais ácido, como, por exemplo, solos ricos em alumínio (YOSHIOKA, LIMA, 2005). No entanto, solos com íons de cálcio $\left(\mathrm{Ca}^{2+}\right)$ e magnésio $\left(\mathrm{Mg}^{2+}\right)$ tendem a ser mais básicos (YOSHIOKA, LIMA, 2005). A escala de pH vai de 0 a 14, indicando pH ácido (0 a 6), pH neutro (7) e pH alcalino (8 a 14) (YOSHIOKA, LIMA, 2005). 
Vanessa Pagno; Fabiana Pagno; Alan Rafael Coineth de Souza; Daniella Rosa Marques de Oliveira.

Diante da necessidade de compreender o conceito de pH do solo e sua relação com os fenômenos mencionados, foi proposta uma atividade com uma técnica alternativa de $\mathrm{pH}$ do solo, durante minicurso ofertado no XXII Encontro de Geografia do Sudoeste do Paraná (ENGESOP), 2019, promovido pelos colegiados dos cursos de Geografia da Universidade Estadual do Oeste do Paraná (UNIOESTE) - Campus Francisco Beltrão, PR. Este minicurso teve como objetivo, explanar os tipos de solos brasileiros, as consequências do intemperismo, com ênfase no conceito de $\mathrm{pH}$ e suas alterações com os tipos de solo.

\section{Metodologia}

A metodologia proposta neste trabalho seguiu duas etapas: explanação dos conceitos sobre tipos de solos, intemperismo e $\mathrm{pH}$ do solo; e atividade interativa e experimental para construção de uma escala de pH e medição do pH de alguns solos amostrais.

Inicialmente, houve a explanação das teorias dos tipos de solo, segundo o Sistema Brasileiro de Classificação dos solos - SISBC (EMBRAPA, 2018), conceitos de solo e suas características, abordando os fatores de formação do solo com ênfase no intemperismo. Em seguida, foi discutido sobre o conceito de $\mathrm{pH}$, sua relação com o solo, como ocorrem as correções de $\mathrm{pH}$ de solo e reações químicas envolvidas. No laboratório, realizou-se a demonstração da análise de $\mathrm{pH}$ de diversos produtos domésticos para a construção de uma escala de $\mathrm{pH}$, indicando os conceitos de pH ácido, neutro e alcalino (YOSHIOKA, LIMA, 2005).

Os produtos domésticos utilizados para a construção da escala de $\mathrm{pH}$ foram: $100 \mathrm{~mL}$ de vinagre de álcool incolor; $100 \mathrm{~mL}$ de vinagre de álcool incolor diluído (solução preparada com $50 \mathrm{~mL}$ de água destilada e $50 \mathrm{~mL}$ de vinagre); $100 \mathrm{~mL}$ de água destilada; $100 \mathrm{~mL}$ de leite diluído (solução preparada com $10 \mathrm{~mL}$ de leite e $90 \mathrm{~mL}$ de água); $100 \mathrm{~mL}$ de solução de bicarbonato de sódio ( $100 \mathrm{~mL}$ de água e $2 \mathrm{~g}$ de bicarbonato de sódio); e $100 \mathrm{~mL}$ de hipoclorito de sódio diluído (90 mL de água e $10 \mathrm{~mL}$ de água sanitária) (Adaptado YOSHIOKA, LIMA, 2005).

Os solos amostrais foram diluídos em água destilada e fervidos em um recipiente apropriado. Após esfriar e sofrer decantação, as amostras foram coadas com coador de café (YOSHIOKA, LIMA, 2005). As amostras de solo foram: Amostra 1 - solo orgânico (coletado em uma horta local); Amostra 2 - solo corrigido com calcário (coletado em uma área de plantio de soja); e Amostra 3 - solo alcalino (manipulado em laboratório). 
Vanessa Pagno; Fabiana Pagno; Alan Rafael Coineth de Souza; Daniella Rosa Marques de Oliveira.

A água com repolho roxo foi preparada com a fervura das folhas em uma panela, seguindo os procedimentos indicados por Yoshioka e Lima (2005). Após esfriar, utilizou-se uma peneira para separar as folhas e resíduos de repolho roxo de seu extrato (Adaptado YOSHIOKA, LIMA, 2005). Posteriormente, o extrato preparado foi armazenado em uma garrafa de plástico, devidamente esterilizada. Para medir o pH de cada amostra preparada, fez-se a adição de $10 \mathrm{~mL}$ de extrato de repolho roxo em cada amostra, sendo este conferido com uso de um medidor de $\mathrm{pH}$ digital.

\section{Resultados e Discussões}

As colocações sobre o tema abordado no minicurso tiveram boa aceitação e os participantes do evento colaboraram com as discussões. O momento com maior destaque foi a análise do conceito de $\mathrm{pH}$, íons presentes no solo e trocas iônicas que ocorrem no solo, pois vários conceitos do dia a dia foram abordados, como a correção do solo e sua relação com a agricultura, uso abusivo de fertilizantes, lixiviação e erosão dos solos.

\section{Atividade prática: Construção de uma escala de pH e medição de pH de solos amostrais}

Os indicadores de $\mathrm{pH}$ mais utilizados para medição do $\mathrm{pH}$ do solo são, em geral, o papel tornassol e a fenolftaleína, que indicam mudança de coloração ao contato com a amostra (ANTUNES et al., 2009). No entanto, um indicador alternativo é o extrato de repolho roxo, que apresenta vantagens em relação a outros métodos pelo fato de ser de baixo custo e de fácil aquisição. Com a adição do extrato de repolho roxo, a cor da solução se altera e indica se o pH é ácido (solução com colorações avermelhadas), neutro (cores lilás e azuladas) ou alcalino (cores mais esverdeadas) (YOSHIOKA, LIMA, 2005).

Para o desenvolvimento da atividade experimental, os participantes foram divididos em quatro grupos e orientados a seguir os procedimentos descritos em um roteiro de aula experimental. Todos os procedimentos foram realizados em conjunto, com discussões após cada resultado obtido, comparando com a escala de $\mathrm{pH}$ que foi disponibilizada. Na Figura 1, pode-se observar a atividade em andamento, com a realização dos procedimentos para a construção da escala de $\mathrm{pH}$. 
Figura 1: Realização da medição do pH de alguns componentes para a construção da escala de pH.

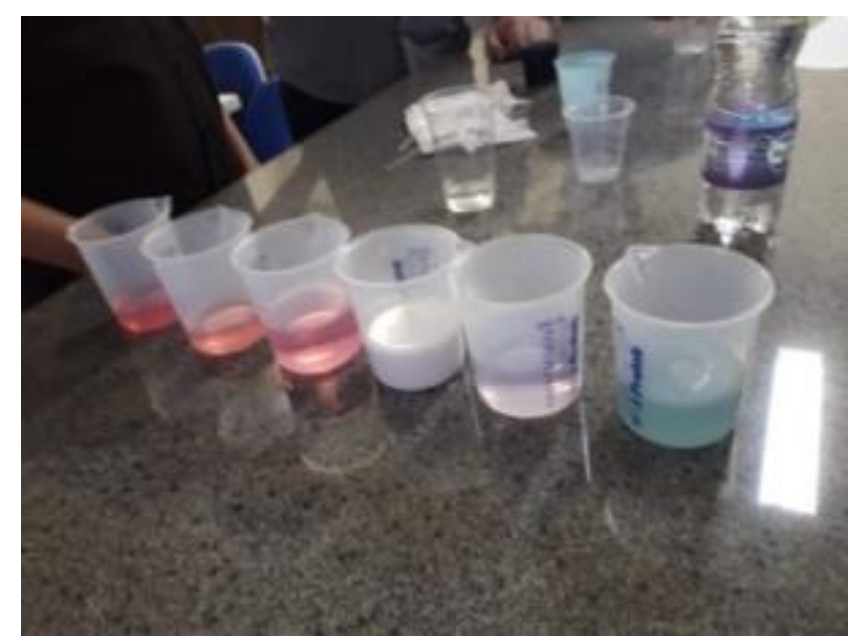

Fonte: PAGNO, 2019.

Os produtos testados na escala de $\mathrm{pH}$ indicaram colorações variadas. $\mathrm{O}$ vinagre de álcool incolor apresentou coloração rosa forte, indicando, $\mathrm{pH}$ ácido. $\mathrm{O}$ vinagre diluído em água também apresentou coloração rosa, no entanto, num tom mais fraco. $\mathrm{O}$ vinagre puro apresentou $\mathrm{pH}$ 2,7 e o vinagre diluído $\mathrm{pH}$ 3. Estes valores confirmam os valores de $\mathrm{pH}$ obtidos por Yoshioka e Lima (2005).

Nas soluções de água destilada e leite, observou-se uma coloração lilás, característico do repolho roxo, indicando que não houve alteração da cor, pois estas soluções são neutras, apresentando pH próximo de 7 (YOSHIOKA, LIMA, 2005).

As soluções de bicarbonato de sódio e hipoclorito de sódio mudaram de cor, indicando uma coloração verde ( $\mathrm{pH}$ 8) e verde-amarelado ( $\mathrm{pH}$ 10), respectivamente. Essas substâncias apresentam pH alcalino, portando, $\mathrm{pH}$ acima de 7 (YOSHIOKA, LIMA, 2005). Assim, obteve-se uma escala de $\mathrm{pH}$, variando valores de $\mathrm{pH}$ de ácido até alcalino, com diferentes produtos e isso facilitou a compreensão do conceito de $\mathrm{pH}$.

Com a medição do pH dos solos, observou-se que o solo orgânico (amostra 1) apresentou coloração rosa, indicando $\mathrm{pH}$ ácido $(\mathrm{pH} 4,5)$ o que indica significativa quantidade de íons $\mathrm{H}^{+}$presentes neste solo (YOSHIOKA, LIMA, 2005). De acordo com Antunes e colaboradores (2009), geralmente, o solo tende a ser ácido, dependendo de sua formação, ou mesmo, devido a ações de intemperismo que removem quantidades significativas de alguns elementos como: Potássio (K); Cálcio (Ca), Magnésio (Mg); Sódio (Na); causam alterações de alguns minerais, ou mesmo o uso de fertilizantes que podem, por exemplo, prejudicar o crescimento de algumas plantas. 
$\mathrm{Na}$ amostra 2, observou-se coloração lilás, indicando $\mathrm{pH}$ neutro (pH 7,0). A correção do solo, geralmente, é realizada com uso de rochas calcárias (SILA et al., 2008) para aumentar o pH, pois a acidez no solo pode ser prejudicial às plantas (KNOPKI, et al., 2020).

$\mathrm{Na}$ amostra 3, observou-se uma coloração esverdeada, indicando pH alcalino (pH 9,6). O solo alcalino tende a apresentar quantidades significativas de cálcio que pode ser incorporado no solo com a adição de calcário para aumentar as quantidades de $\mathrm{Ca} 2+$ (YOSHIOKA, LIMA, 2005; KNOPKI, et al., 2020), ou mesmo em locais com poucas chuvas, reduzindo as ações do intemperismo da água, que tende a carrear o cálcio do solo (ANTUNES et al., 2009). Desta maneira, o solo precisa apresentar $\mathrm{pH}$ próximo ao neutro para equilibrar os íons presentes no solo e auxiliar os vegetais na obtenção de nutrientes mais importantes.

Na Figura 2, observa-se alguns dos resultados obtidos e a preparação para iniciar o procedimento com as amostras de solo. Após a realização da medição do pH com o repolho roxo, os $\mathrm{pH}$ dos componentes foi conferido com o uso de um medidor de $\mathrm{pH}$ digital.

Figura 2: Preparo da escala de $\mathrm{pH}$.

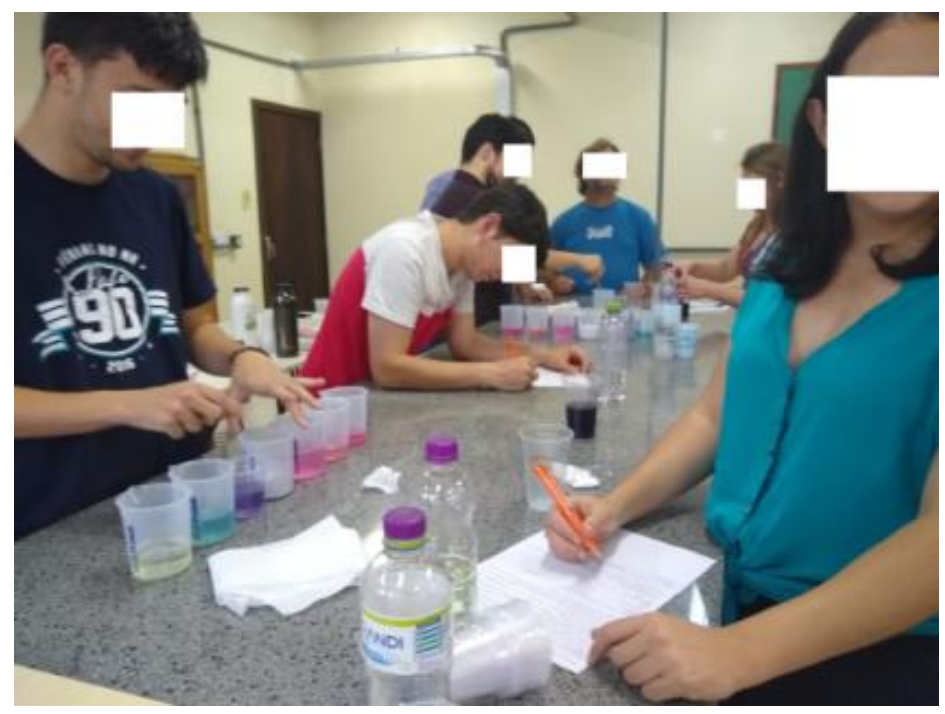

Fonte: PAGNO, 2019.

Após as diversas discussões sobre as análises de $\mathrm{pH}$ realizadas, os questionamentos e comentários passaram a abordar as mais variadas substâncias encontradas no dia a dia e qual seria o pH correspondente. Além disso, foi reforçada a ideia de que cada solo apresenta $\mathrm{pH}$ diferente, dependendo da região em que se encontra, se está mais na superfície ou mais profundo, ou mesmo se este sofre ações antrópicas ou de intemperismo (KNOPKI et al., 2020). 


\section{Dinâmica dos Solos Brasileiros e Técnica Alternativa para Medição do pH do Solo, utilizando Extrato de}

Repolho Roxo

Vanessa Pagno; Fabiana Pagno; Alan Rafael Coineth de Souza; Daniella Rosa Marques de Oliveira.

\section{Considerações finais}

Com as atividades realizadas, foi possível abordar os conceitos de tipos de solo, intemperismo do solo e sua influência no $\mathrm{pH}$, bem como o conceito de $\mathrm{pH}$ e íons trocáveis do solo com uma abordagem diferenciada e interativa. Os participantes puderam compreender com a prática o que é o pH e como ele pode ser medido, por meio da obtenção de uma escala de $\mathrm{pH}$ e da medição de $\mathrm{pH}$ de amostras de solo. Foi possível construir uma nova visão deste conceito relacionando com compostos do dia a dia e com os tipos de solos brasileiros, bem com as ações antrópicas e de intemperismo. Desta maneira, as experiências vivenciadas neste minicurso foram relevantes para os participantes e podem ser repetidas em sala de aula, em escolas, por exemplo, uma vez que se trata de experiências simples e com materiais de fácil acesso. Além de permitir a abordagem de diferentes temas ligados tanto à Geografia quanto à Química.

\section{Referências}

ANTUNES, Márjore; ADAMATTI, Daniela S.; PACHECO, Maria Alice R.; GIOVANELA, Marcelo. pHdo Solo: Determinação com Indicadores Ácido-Base no Ensino Médio. Química Nova na Escola, v. 31, p. 283-287, 2009. Disponível em: <http://qnesc.sbq.org.br/online/qnesc31_4/11-EEQ-3808.pdf>. Acesso em: 20 jul. 2019.

KNOPKI, Anna Vitória Gurgel, [et al], (orgs). Experimentos na Educação em Solos. Marcelo Ricardo de Lima. Programa de Extensão Universitária Solo na Escola/UFPR. Curitiba, 2020.

LEÃO, Marcio Fernades; BARROSO, Emílio Velloso; POLINANOV, Helena; MARQUES, Eduardo Antônio Gomes Marques; VARGAS Jr, Eurípedes do Amaral; FIGUEIREDO, Veronica Dutra de. Aspectos Mineralógicos, Químicos e Físicos de Frente de Intemperismo em Filtro da Formação Batatal, Quadrilátero Ferrífero, Anuário do Instituto de Geociências UFRJ, Vol. 40, p. 398-406, 2017. Disponível em: <http://www.ppegeo.igc.usp.br/index.php/anigeo/article/view/12932>. Acesso em: 21 jul. 2019.

SANTOS, Humberto Gonçalves dos; JACOMINE, Paulo Klinger Tito; ANJOS, Lúcia Helena Cunha dos; OLIVEIRA, Virlei Álvaro de; COELHO, Maurício Rizzato; ALMEIDA, Jaime Antonio de; ARAÚJO FILHO, José Coelho de; OLIVEIRA, João Bertoldo de; CUNHA, Tony Jarbas Ferreira. Sistema Brasileiro de Classificação de Solos. EMBRAPA. 5 Ed. Brasília, 2018.

SARDINHA, Diego de Souza; GODOY, Letícia Hirata; CONCEIÇÃO, Fabiano Tomazini da. Taxa de intemperismo químico e consumo de $\mathrm{CO}_{2}$ em relevo cuestiforme com substrato basáltico e arenítico no estado de São Paulo, Brasil. Revista do Instituto de Geociências, v. 19, p. 177-134, 2019. 2 Disponível <http://ppegeo.igc.usp.br/index.php/GUSPSC/article/view/13205>. Acesso em: 22 jul. 2019. 
SILVA, Tiago Roque Benetoli; LEMOS, Leandro Borges; CRUSCIOL, Carlos Alexandre Costa; PAULY, Tatiane. Alterações de atributos químicos do solo em função da calagem superficial em plantio direto. Agrarian: Revista científica da Faculdade de Ciências Agrárias, v. $1, \quad$ p. $9-20, \quad 2008 . \quad$ Disponível em: <https://ojs.ufgd.edu.br/index.php/agrarian/article/view/24>. Acesso em: 22 jul. 2019.

YOSHIOKA, Maria Harumi; LIMA, Marcelo Ricardo de. Experimentoteca de solos: pH do solo. Projeto de Extensõa Universitária Solo na Escola: Departamento de Solos e Engenharia Agrícola da UFPR, 2005. Disponível em: 〈https://www.sbcs.org.br/wpcontent/uploads/2012/09/experimentotecasolos7.pdf>. Acesso em: 22 jul. 2019. 